\title{
Policy Framework Surrounding Women Economic Participation in Jordan
}

\author{
NAHIDA EL-SAIES
}

TVET \& Gender Specialist

Amman -Jordan

\section{Introduction}

\section{Women situation in the MENA Region countries}

Women situation in the MENA Region countries, have long lived under difficult economic and social conditions, have the worst gender equality rankings according to the Global Gender Gap Index $2017^{1}$.

(The Global Gender Gap report is an annual insight report that is carried out by the World Economic Forum. This tool shows vital gender-based indicators to determine the performance of each of the selected 144 countries.)

Some of these indicators are: i) economic participation and opportunity, ii) health and educational attainment, iii) political empowerment, vi) workforce, v) skill sets, and vi) educational degrees.

The status of women in MENA is at a critical point. Violence and instability in the region have made gender issues a lower priority for MENA governments. Furthermore, because of external interference, the population in MENA, including women, is re-embracing cultural traditions and attachments, giving more validity to conservative forces within their countries.

When the Arab women are compared to other countries women in the world, the Arab women are considered as the lowest labour participation rate, about $25 \%$, which is almost half the rate for women in the European Union and by far one of the lowest rates in the world. In addition, they have low literacy rate, low income, and high unemployment.

In Jordan the conflict and instability situations in the surrounding neighboring countries, and for many years, have aggravated and weaken the economic conditions, with increasing the unemployment rate and

${ }^{1}$ http://www3.weforum.org/docs/WEF_GGGR_2017.pdf 
decline the standards of living in Jordan. This impacted severely on the Jordanian women.

Jordan has more than $3 \%$ a relatively high population growth rate and a young population structure. More than one third of the population is younger than 15 years old, while those aged over 60 accounted for 5 to $6 \%$ of the total.

There is a preference for larger families, with women reporting a mean ideal family size of 3.9 children in average. There is no difference reported between rural and urban areas.

\section{Access into the labour market}

\section{Forces affecting women economic inactivity}

Women economic inactivity in Jordan reflects the social, economic, and political forces that pull women out of the economy, or keep them in the bottom strata of the economic structure, some of these forces are:

- Most female employment in Jordan are constituting the right of the women's husband or family, rather than the woman herself.

- Due to scarcity in job opportunities creates an impression that employing women will certainly reduce opportunities for male, who are considered the main source of income, but this assumption is not true as there is no correlation between high rate of unemployment and female labour force participation.

- Employers who prefer female workers offer them jobs that are low skilled and low paid. While other employers prefer male job seekers

- Women prefer to get jobs in the public sector than in the private sector, and prefer to wait longer periods of unemployment for public sector jobs as they offer them better remuneration and benefits.

- Most MENA countries have labour laws that, while designed to protect women, result in higher costs for employers who hire women. Such as laws on the number of hours of work for women (flexy hours), maternity leave, provision of childcare, and transportation.

- "discouragement." is another important issue, a person who is discouraged is inactive because he or she feels a job search would be a useless effort. In addition, women face higher unemployment rates, 
with less job opportunities than men, and social barriers to entering labour markets, discouragement among women is higher than among men. Since no available data on discouragement, makes it difficult to put any conclusions on the severity of this problem.

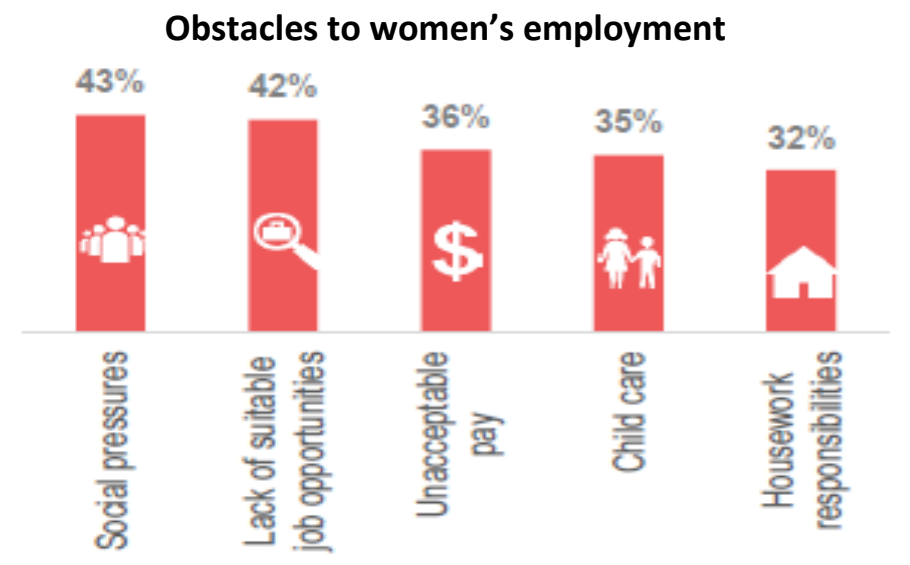

\section{Jordanian Women in the labour force:}

Politics in Jordan largely remains a male domain. Decisions are taken by men and therefore are serving predominantly the male interests and needs.

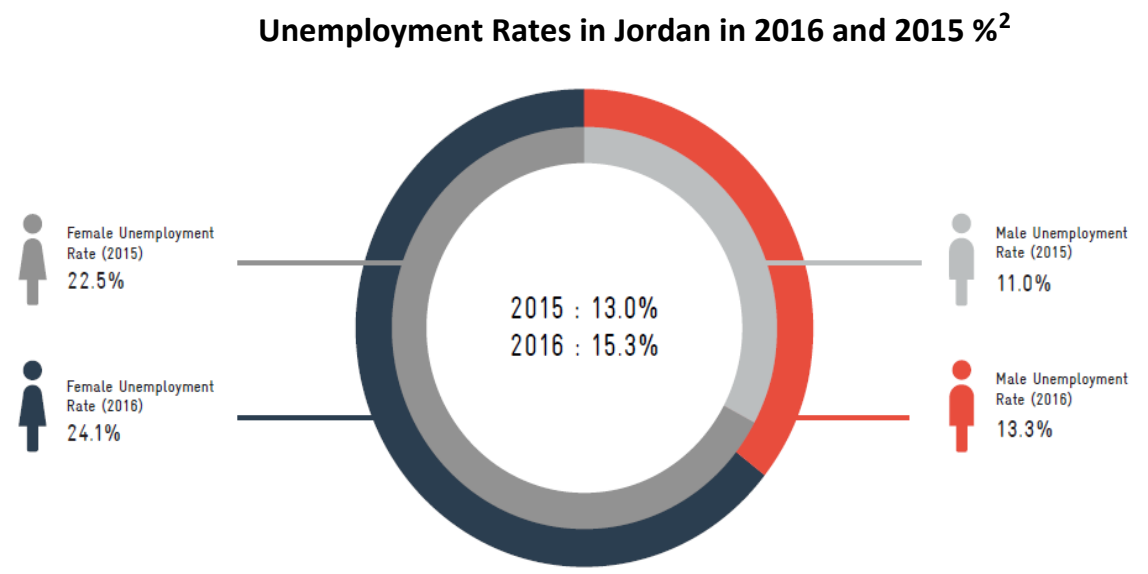

Women in the labour force are affected more by unemployment. Strikingly, their unemployment is increasing it moved form $24.1 \%$ in 2016 to 33\% in 2017.

Women economic role continue to be undermined perceiving her as the care giver, or in case of employment she is expected to perform the dual

\footnotetext{
2 DOS Employment and Unemployment Survey 2016
} 
roles. The social and economic structures do not offer women the conducive environment where she retains her job, succeed, or advance in her career. This means their economic participation would require the availability of high quality jobs that jobs are available and could be offer in the industrial sector.

However, the picture has a bright side. Women in Jordan try to meet these challenges, by increasingly joining the labour force as entrepreneurs, startup small-scale enterprises, often from home, driven by the need rather than the choice.

\section{Female economic participation Frameworks}

Studies show a strong correlation between women's economic participation and a country's general economic growth and well-being. Women have a different approach towards their families and communities; they reinvest $90 \%$ of their earnings in their families and communities, compared with men, who reinvest only $30 \%$ to $40 \%$ of their income ${ }^{3}$.

Obviously supporting women's economic participation brings substantial dividends to families, communities, and to the economy. This means that investing in women is an investment in our collective future.

When women are empowered as economic actors, they simultaneously are empowered as social and political actors.

In Jordan female economic participation continues to be extremely low in 2016 comparing males to females' participation, was $18.2 \%$ for females while male's participation was $81.8 \%$. The World Economic Forum Gender Gap report 2017 places the lower middle-income country Jordan directly on place 135 from 144 countries. While Yemen that ranks in the 


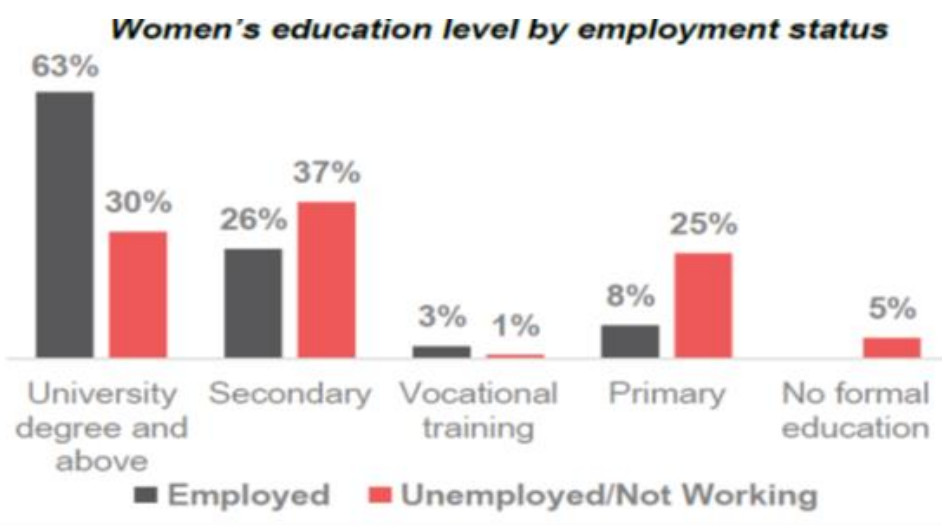

lowest 144 from 144 countries according to" The World Economic Forum Gender Gap report 2017”. The table shows rankings of the Countries of Middle East and North Africa region, $2017^{4}$.

\begin{tabular}{lll}
\multicolumn{3}{c}{ MIDDLE EAST AND NORTH AFRICA } \\
\hline $\begin{array}{c}\text { Overall } \\
\text { rank }\end{array}$ & $\begin{array}{c}\text { Overall } \\
\text { Score }\end{array}$ \\
\hline Country & 117 & 0.651 \\
\hline Tunisia & 120 & 0.649 \\
\hline United Arab Emirates & 126 & 0.632 \\
\hline Bahrain & 126 & 0.629 \\
\hline Algeria & 127 & 0.628 \\
\hline Kuwait & 129 & 0.626 \\
\hline Qatar & 130 & 0.625 \\
\hline Turkey & 131 & 0.614 \\
\hline Mauritania & 132 & 0.608 \\
\hline Egypt & 134 & 0.604 \\
\hline Jordan & 135 & 0.604 \\
\hline Morocco & 136 & 0.598 \\
\hline Lebanon & 137 & 0.596 \\
\hline Saudi Arabia & 138 & 0.584 \\
\hline Iran, Islamic Rep. & 140 & 0.583 \\
\hline Syria & 142 & 0.568 \\
\hline Yemen & 144 & 0.516 \\
\hline
\end{tabular}

According to DOS women who have jobs are in general with better education than the women who are unemployed. nevertheless, most women who do not work have completed high school and or higher education.

It is worth noting that the unemployment rate is high among women who have high educational degrees as Bachelor and above. Consequently, educational level dose not explain why Jordanian women are unemployed and inactive.

${ }^{4}$ http://www3.weforum.org/docs/WEF_GGGR_2017.pdf 
The membership of Jordanian women in professional associations has been growing but remains largely limited to associations of typically "female" professions. Only $1 \%$ of members in the chambers of commerce are women and $5 \%$ in the chambers of industry.

\section{Gender-based discrimination through various laws}

- The Jordanian Personal Status Law (2010) allows the guardian or the husband to prevent women from working if it is perceived that doing so would harm the family's unity. A woman can only object to her husband's decision if she has a condition in the marriage contract which states that her husband cannot prevent her from working, a right that is not usually exercised or is not known to the majority of women.

- Jordanian women cannot pass their nationality to their husbands and children. This issue is conceptually linked to citizenship and the definition of a citizen in accordance with male standards. Great efforts by NGOs to make changes to the Jordanian Constitution to add a reference to non-discrimination based on sex in Article 6, which currently stipulates, (Jordanians shall be equal before the Law. There shall be no discrimination between them with regards to their rights and duties, on grounds of race, language or religion).

- The amendment of the Constitution was proposed to the government, but the proposed change to the Article 6 was rejected.

\section{Gender-based sector segregation}

female employees represent $58 \%$ of the workforce at the Ministry of Education, Ministry of Social Development, and Ministry of Health.

The higher number of females at these ministries is a result of various factors:

- the jobs at these ministries (teachers, nurses, social workers) are highly acceptable for women in the society

- men tend to prefer job opportunities in the private sector and other government sectors because of more attractive salaries and benefits 
- women, being 'financially dependent', tend to favour the Public Sector as working hours are shorter and Public-Sector work offers some job security such as health insurance and social security

- the higher representation of women at the three mentioned ministries does not indicate a high representation at the senior level!

In the education, health, and services sectors, of jobs held by female workers, it exceeded the anticipated rate, meaning that most female workers not only favor joining the lower-growth sectors, but also those with lower labor productivity (education, health, services).

The lowest percentage in the sector segregation of women is in the:

- religious and Islamic affairs sector (7.6\%), followed by

- $17.5 \%$ in the transport sector,

- $18.9 \%$ in the natural resources sector, and

- $23.8 \%$ in the infrastructure services and communications sector.

most jobs at these ministries are jobs for men that need certain qualifications such as that of being an Imam (male preacher), which comprise most of jobs at the Ministry of Religious and Islamic Affairs, or jobs at the Ministry of Transportation, which mainly recruit male drivers.

In the amended Labour Law (2008) introduced in Article 29 a punishment of any sexual harassment of employers/employees who approve of committing such acts against his/her/other employees.

\section{Gender- wage earning segregation}

The Jordanian women earn, on average, $10 \%$ less in wages than $\mathrm{men}^{5}$, but this difference is much higher for professionals, such the female legislators, senior officials, and managers, who are paid about $32 \%$ less than their male peers $^{6}$. In terms of average nominal wages, this translates to 336 JD approximately 480 USD for women and 419 JD approximately 600 USD for men - measured in the public sector. The national retirement age for women is 55 years and for men for 60 years $^{7}$. Which means that men tend 
to work more years to add to their retirement, and this will lead to have better retirement salary than women.

Women participation in the labour force has increased in the recent years, with educated women more motivated to achieve their own economic independence and the poor working more for economic reasons, it reached $18 \%$ in 2016. However, it is still one of the lowest in the world, with a wide gender gap, affecting the most the vulnerable women who are poor, with low education, and with high marital status gap in women participation.

\section{Gender roles and women's workforce participation}

Rigid gender roles within the Jordanian society pose as serious barriers standing in front of women's workforce participation due to the following:

- culturally it is expected from the women to be primarily the caretaker of children and the household,

- women who are having a job is a secondary option she can pursue on the condition that she can still fulfil the household and family needs meanwhile - and only if her husband allows her to do so.

- The laws and policies are shaped by these cultural norms, widening the gender gap even further. For example, the husband can legally deny the wife from working if it harms the family unity.

Gender roles and systematic inequalities towards women can be attributed to the underrepresentation of women in the public administration and decision-making roles, the lack of women perspectives in public keeps the status quo very difficult to change. Women also suffer from the negative social perception towards them in workplaces as well. While it is forbidden to discriminate by law, women in the public-sector face prejudice when getting a job, being appreciated, and being promoted.

\section{Labour code gives rights for women}

The labour code gives the right for women as the following:

- 70 days paid maternity leave

- Protection of pregnant women from being fired. 
- enables married women to take one year of unpaid leave to raise a child,

- if number of women works in a company with more than ten employees then she is permitted to work one hour less to nurse her child.

- Women have the right also to take up two unpaid years of leave to accompany their husbands

- There is an article no 72 in the labour law that requires companies with more than 20 employees to provide child care facilities, if there are 10 of the children under four years, while this law is not applicable to women working in the public sector.

A study conducted in 2015 by the Higher Population Council states that only $5 \%$ of companies that employ 200 employees or less provide child care, and only $13 \%$ of bigger companies (more than 200 employees) provide it. These laws are highly discouraging employers from hiring women, especially with the burden of paying women while on maternity leave leading to a (marital-status gap) of about $24 \%$.

The regulatory employment environment also entails some ambiguous gender rules such as prohibiting women work at night between 7PM and 6AM (with exception of certain sectors), and from taking up employment in certain jobs.

\section{Assessment and supporting Interventions in Jordan with potential of female employment}

The Jordanian economy trapped in low-growth equation, the labor market continues to be weak and structural unemployment remains high. The unemployment rate in Jordan reached $18.5 \%$ in the third quarter of 2017, reported Department of Statistics (DOS). The unemployment rate among males stood at $15.4 \%$ and $30 \%$ among females in the same period.

\section{Characteristics' of the unemployed:}

- The unemployment rate was high among university degree holders at $39.1 \%$ compared to other educational levels. 
- $6.0 \%$ of the total unemployed are secondary school graduates and $46.0 \%$ of the total unemployed had lower than secondary educational qualifications.

- The percentage of unemployed persons varied by educational level and gender. The percentage of unemployed males with bachelor's degree or higher was $24.7 \%$ compared to $76 \%$ for females.

\section{Distribution of Jordanian Unemployed persons age 15+ years by educational level and Sex (\%), $2016^{8}$}

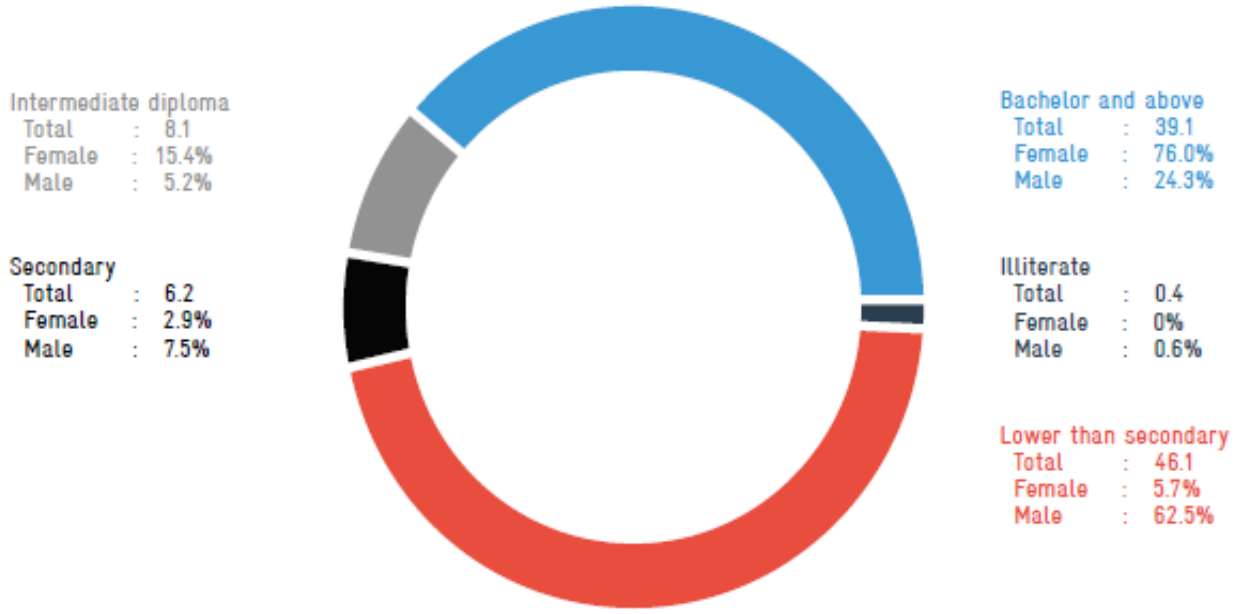

Jordan known to have lagged MENA and non-MENA averages of female labor force participation. Accordingly, unemployment for women averaged $33.5 \%$, while the unemployment rate for males averaged $13.7 \%$ in 2017.

The private and public sectors are legally required to maintain gender equality and nondiscrimination. In practice, gender discrimination is common. In the public sector:

- Most, managerial positions favor men.

- Women must earn higher degrees than men to gain access to the same positions and benefits.

- Bonuses and promotions are skewed towards men due to the idea that males as breadwinner are more deserving.

In the private sector discrimination is more prevalent and preference in employment is skewed towards males,

${ }^{8}$ DOS Employment and Unemployment Survey 2016 
- women need to take maternity leave and other leaves due to the commitments to her family needs, that do not please private sector employers.

\section{Governmental policies in Jordan supporting women's entrepreneurship are insufficient.}

Whereas recently the government launched the regulations that allow practicing some professions from home. This will help women's entrepreneurship for trading with other businesses and diversifying their markets, and increase their income bracket. A total of 59 jobs as (Home Based Businesses) were listed and can be practiced from home, this regulation would be mainly suites women to avoid the difficulty in transportation, and house work obligations.

\section{Additional targeted policies need to be taken by the government}

There is a need for the government to take more action targeted policies such as:

- Tax exemptions while home based businesses income tax exempted for an amount ranges for $300-1500 \mathrm{JD}$ as this is already not included in the tax brackets.

- Easier registration procedures for companies and small businesses at both the formal and informal levels is required to help women develop and expand their business. Entrepreneurs and starting up businesses are required to submit a leasing contract for a facility in trade-zoned areas. This puts a cost burden on women entrepreneurs in their start-up phase.

- Until today there is no clear and comprehensive policies or strategies on the national level that tackle the challenges that women entrepreneurs are facing or even gives any incentives for women to enter the labour market.

- Many donors and local NGOs worked on suggesting policies to enhance women economic participation but most of the recommendations are focusing on the employment in general and not on women entrepreneurship and development and to support of micro and small enterprises. 
Supporting women should be taken in to consideration cultural and traditional obstacles as well as the willingness of women to achieve something new for their own progress.

Necessary awareness raising processes for local population through trusted third parties (service providers, municipalities, CBO's donors etc.).

\section{Enhanced women's economic empowerment}

An effective way to address female unemployment and to help enhance women's economic empowerment in remote/rural areas is promoting women's entrepreneurship throughout the following:

- enhance home based businesses to facilitate women's work from homes, but with good training, guidance, and supervision in cooperation with (local) authorities.

- cooperation and networking of the interested women from the same field should be practiced from the beginning of an intervention to avoid competition among the women of the same business.

- Networking and cooperation are the appropriate ways for further improvement of employment related activities, e.g. open a shop for cloth repair and selling sewed products by a group of women.

- Another option could be a productive kitchen, managed by group of women who wants to cook and bake traditional food.

- With clear orientation for cooperation and trainings on marketing, management with legal procedures implementation how to establish a business the step into the semi-formal or formal labour market could be comprehended.

\section{Conclusion}

obstacles to equality: gender equality and the empowerment of women is ambitious targets for ending all forms of discrimination against women, eliminating all forms of violence and harmful practices, improving economic empowerment and access to productive assets and technologies, and enhancing the female voice and decision-making power.

Increasing women's income-earning opportunities and their access to productive assets provides a direct pathway out of poverty. 
- Economic empowerment can give women voice to manage their own money and make decisions for themselves and their family.

- Fewer women than men are economically active, and women often occupy less secure and lower paying jobs than men or choose jobs that offer flexible hours, allowing them to balance work and household responsibilities. And more women than men are contributing family workers. These jobs are often insecure, do not provide any contractual security or benefits, and offer limited opportunities for career advancement and higher wages. Men also dominate firm ownership and management.

- Access to financial services is another vehicle of economic empowerment, allowing women to borrow and save to start a business, cope with economic shocks, and invest in their family's future. But in many countries as well in Jordan women face more barriers than men do in opening a bank account, such as the need for a male family member's permission, the lack of documentation to prove identity, and lack of information.

- Focused training assistance is needed for women in Jordan, which can be provided through specialized courses that would be offered by the NGOs, or by municipalities/ with the help of those NGOs.

- Women entrepreneurs need training in the basics of business management, such as basics in cost accounting. Other need training in all marketing skills starting from nice colours, good design, quality crafts, creativity and packing skills...etc.,

- Most women entrepreneurs specifically need assisting in promotion of their products or services.

Most of the women are operating informally from their homes for the small businesses, because of costly registration and licensed fees. Additionally, most of women are unaware of the legal details that may affect their businesses; they feel that complicated registration processes are the main reason for operating informally. In general, lack of knowledge of the laws and regulations to establish a business is the main reason for not registering 
their business. As well, the lengthy and complex registration and licensing procedures discourage women from going through the official process. Also, as long they do not need to apply for a loan they do not see additional benefits in registering their business.

Most women started their business alone using their savings, with support from their families and husbands that were supportive mainly for the following reasons:

- Most of the customers are women so the direct interaction is with women.

- Women are contributing to increase the family income.

- Women own their business or work from home, so they work flexible hours and can simultaneously take care of their children.

most women are employing 1-3 employees who are mostly family members, including their husband. while most of these women are not aware of the need to account for a monthly salary for themselves as managers. Ignoring this and other costs such as rent, water and electricity costs, when calculating the net income of their businesses, leads to false judgment on the business performance. This is a main reason of failure when moving to operate formally.

\section{Recommendations}

- There is a need to promote work-life balance and emphasize the importance of sharing family responsibilities, high quality childcare and adult care facilities, paternity leave, affordable and subsidized family support services.

- Develop specialised training programmes of technical and vocational skills that focus on practical training experience.

- Develop a public administration gender equality strategy and implementation plans/programmes of gender equality with adequate resources.

- Introduce gender budgeting within the Ministry of Finance, including an internal staffing focus to support gender balance and gender equality 
- Advocate for targets or quotas for women in leadership positions in the public administration.

- Building the capacity of female employees in the public sector and training civil servants on gender-related issues.

- Coordinate campaigns with the Jordan National Committee for Women (JNCW), and other related NGO's for changing attitudes towards women and their leadership capacity.

With more input from the different parties, there may be greater prospects of improving women's access to employment, the range and quality of work they have undertaken within them, and the possibilities of working out of poverty. 